\title{
Patient and physician perspectives on the use of cyclosporine ophthalmic emulsion $0.05 \%$ for the management of chronic dry eye
}

This article was published in the following Dove Press journal:

Clinical Ophthalmology

\author{
Tatiana Deveney' \\ Penny A Asbell ${ }^{2}$ \\ 'Ophthalmology \& Visual Sciences, \\ Kellogg Eye Center, University of \\ Michigan, Ann Arbor, MI, ${ }^{2}$ Department \\ of Ophthalmology, Icahn School of \\ Medicine at Mount Sinai, New York, \\ NY, USA
}

\begin{abstract}
Dry eye disease (DED) is a multifactorial disease of the ocular surface and is one of the most common reasons for patients to visit an eye care provider. Cyclosporine A (CsA) is an immune modulating drug that was approved in the US for topical use in the treatment of DED in 2003, which led to a paradigm change in our understanding and treatment of DED, turning attention to control of inflammation for treatment. This review summarizes the literature to date regarding the impact of CsA on the treatment of DED. A special focus is given to the patient and physician perspectives of CsA, including dry eye symptom improvement, medication side effects, and overall patient satisfaction. Studies evaluating CsA in DED have considerable heterogeneity making generalized conclusions about the effect of CsA difficult. However, most studies have demonstrated improvement in at least some symptoms of dry eye in CsA-treated patients. Side effects, most commonly ocular burning on administration of CsA, are common. The literature is sparse regarding long-term follow-up of patients treated with CsA, optimal duration of treatment, and identifying which patients may receive the most benefit from CsA.
\end{abstract}

Keywords: dry eye, cyclosporine, inflammation

\section{Introduction}

Dry eye is a multifactorial disorder of the ocular surface and tear film that affects between $5 \%$ and $34 \%$ of people globally and is estimated to result in $>\$ 3$ billion in direct costs in the US annually. ${ }^{1-3}$ Symptoms include eye pain, discomfort, and visual distortion and can negatively impact patients' quality of life. ${ }^{4}$

Dry eye disease (DED), for many decades, was primarily treated as an abnormality of the tear film to be treated with lubrication. Introduction of topical cyclosporine led to a paradigm shift in understanding the pathogenesis and treatment of DED. The dry eye workshop (DEWS) published an extensive review on DED in 2007 and includes inflammation in the definition of DED. ${ }^{5,6}$ Review of the scientific literature over the last decade shows the increasing interest in inflammation associated with DED in both animal models and clinical trials of patients with DED. ${ }^{5}$ There have been multiple randomized clinical trials on anti-inflammatory agents, including the recent Food and Drug Administration (FDA)-approved lifitegrast for DED. ${ }^{7}$ Cyclosporine $\mathrm{A}(\mathrm{CsA})$ is a calcineurin inhibitor that interferes with $\mathrm{T}$ cell function and was initially used clinically as a systemic immunosuppressive agent to prevent rejection after organ transplantation. The use of topical CsA to treat ocular inflammation, including dry eye, was first investigated in the 1980s and ultimately lead to
Correspondence: Penny A Asbell Department of Ophthalmology, Icahn School of Medicine at Mount Sinai, 17 East 102nd Street, New York, NY 10029, USA

Tel + I 2I2 24I 7977

Email penny.asbell@mssm.edu 
several large clinical trials that resulted in FDA approval of cyclosporine ophthalmic emulsion $0.05 \%$ (Restasis ${ }^{\circledR}$ Allergan, Inc., Irvine, CA, USA) in $2003 .^{8-10}$ The indication for FDA approval of CsA in the US is "to increase tear production in patients whose tear production is presumed to be suppressed due to ocular inflammation associated with keratoconjunctivitis sicca." 10 CsA is now discussed as a dry eye treatment option in the American Academy of Ophthalmology Preferred Practice Pattern for dry eye management ${ }^{11}$ and an estimated $48.2 \%$ of chronic dry eye patients fill a prescription for CsA. ${ }^{12}$

The goal of this review is to summarize the current evidence regarding the use of CsA for the treatment of dry eye with a focus on the patient and physician perspective and to highlight areas of continued uncertainty and topics for further research.

\section{Patient perspective on the use of topical cyclosporine $\mathbf{0 . 0 5 \%}$}

A number of studies, ranging from observational case series to randomized controlled clinical trials, have been conducted to evaluate the efficacy of CsA for DED (Table 1). The evidence to date, however, is difficult to evaluate cohesively as studies vary significantly in design (including use of a control group), inclusion criteria, length of follow-up, and outcome measures evaluated. ${ }^{13}$ Many of the postFDA-approval studies of CsA have also been sponsored by Allergan, Inc., the maker of Restasis; this is not unique to CsA, with one systemic review of dry eye treatment trials finding that $78 \%$ were sponsored by the pharmaceutical industry. ${ }^{13}$

\section{Standard signs as a measure of DED}

Most studies of DED include change in signs, such as ocular surface staining and Schirmer score, and report improvement with topical CsA treatment. The initial safety and efficacy studies of CsA involved over 1,000 patients randomized to

Table I CsA and dry eye - different study designs

\begin{tabular}{ll}
\hline Study type & References \\
\hline Meta-analysis/systematic review & $(8,18,19)$ \\
Randomized controlled trial & $(14,15,17,25,42,43,47,60)$ \\
Prospective observational studies & $(20,21,26,30,36,53,56-58)$ \\
Retrospective & $(33,39,41,46)$ \\
Clinician perspectives & $(14,23,39)$ \\
Patient surveys & $(29,35)$ \\
Health expenditure data & $(12,5 I)$ \\
\hline
\end{tabular}

Abbreviation: CsA, cyclosporine A.
CsA (of varying concentrations, including $0.05 \%$ ) or vehicle control and reported statistically significant increases in Schirmer wetting in patients treated with CsA. ${ }^{14,15}$ FDA approval was subsequently based on improvement in tear function in $59 \%$ of patients. ${ }^{16}$ A subsequent randomized controlled trial by Chen et al performed in Chinese patients found that there was a similar improvement in corneal staining and Schirmer score. ${ }^{17}$ In two meta-analyses of studies evaluating CsA for dry eye, a statistically significant increase in Schirmer score was noted in patients treated with CsA versus controls. ${ }^{18,19}$ Tear film break-up time has also been demonstrated to increase with CsA treatment, ${ }^{20}$ with a meta-analysis by Wan et al reporting improvement in this measure by 2.30 seconds in CsA-treated patients. ${ }^{19}$ Postapproval (Phase IV) open-label studies of CsA have also demonstrated improved ocular surface staining, Schirmer test score (average increase from 5.3 to $8.7 \mathrm{~mm}$ ), and tear film break-up time. ${ }^{21}$

\section{Patient-reported measures of DED Dry eye symptoms}

Given the multifactorial nature of DED and its variable clinical presentation and diagnosis, it is not surprising that there is often a poor correlation between dry eye signs and symptoms. ${ }^{22}$ This is one of the challenges in diagnosis and management of DED and is an important consideration when evaluating clinical trials of DED. Change in patient-reported symptoms of DED may not correlate with physician-measured outcomes. Furthermore, $69.7 \%$ of eye care providers reported that patient history had the largest impact on guiding therapeutic effect for dry eye. ${ }^{23}$ Almost all of the CsA studies in the literature also report on patient-centered outcomes, such as improvement in dry eye symptoms and use of artificial tears. There is considerable variability, however, in how such outcomes are measured with some studies assessing patient response by patient diary and others using more global scores, such as the Ocular Surface Disease Index (OSDI), a validated questionnaire that provides a global assessment of patient experience of DED through evaluation of ocular symptoms, vision-related function, and environmental triggers. ${ }^{24}$ In general, improvement in at least one dry eye symptom was observed with CsA use. Improvement in any particular symptom of DED, however, was not consistent across studies.

In the pilot dose-response study of CsA, treated patients reported significant improvement in sandy or gritty feeling and dryness compared to vehicle. ${ }^{15}$ In the larger follow-up trial that evaluated 877 patients for 6 months, there was a 
statistically significant improvement in blurred vision among CsA patients. Although there was improvement in the symptoms of sandy or gritty feeling and itching in CsA patients, it was not statistically significant compared to controls. ${ }^{14}$ A randomized controlled trial in a Chinese patient population demonstrated improvement in ocular dryness and foreign body sensation with CsA treatment. ${ }^{17}$ In the control group not treated with CsA as well, many dry eye symptoms improved over the course of the study period.

Several studies have compared CsA versus other topical treatments for dry eye including artificial tears, ${ }^{25}$ diquafosol sodium $^{26}$ (a P2Y receptor agonist that promotes aqueous and mucin secretion and which is not approved for use in the US) and vitamin A. ${ }^{27}$ Park et al evaluated 167 patients randomized to $\mathrm{CsA}$ versus varying concentrations of sodium hyaluronate artificial tears. All patients reported significant improvement in OSDI score over the course of the study with a range in mean change from 12.07 in the $0.3 \%$ sodium hyaluronate group to 17.93 in the CsA group. There was no statistically significant difference in OSDI score improvement between treatment groups. ${ }^{25}$ Similarly, in a non-randomized study comparing CsA versus diquafosol, all patients had improvement in dry eye symptoms without a statistically significant difference between groups. ${ }^{26}$ In a study comparing CsA versus vitamin A versus neither, CsA-treated patients reported significant improvement in blurred vision compared to untreated patients, but there was no significant difference between the CsA and vitamin A groups. ${ }^{27}$

By design, randomized controlled trials are performed under controlled conditions and therefore may not be generalizable to the real-world patient experience and usage of a medication. ${ }^{28}$ Studies evaluating patient response outside of a randomized clinical trial, therefore, have a practical value. In a study by Stonecipher et al, 5,884 patients recruited from ophthalmologist, optometrist, and primary care physician offices completed a telephone survey prior to starting CsA for dry eye and at 30- and 60-day follow-ups. No exam-based correlation was obtained and no control group was concurrently assessed. Patients reported that dry eye symptom severity was significantly decreased from baseline at 30 and 60 days after starting CsA and there was also a decrease in the impact of dry eye on daily activities (eg, watching television and driving). Similar improvement in symptoms was found among patients with varying length of dry eye diagnosis prior to starting CsA. ${ }^{29}$

Post-FDA-approval observational studies of CsA have also been performed. In the IMPACT study sponsored by Allergan Inc., 40 dry eye patients were treated with CsA for
6 months. The average OSDI score significantly improved from 47.0 to $26.8 .^{21}$ This degree of improvement is greater than the reported minimally clinically important difference for the OSDI (range from 7.0 to 9.9 for all dry eye patients) ${ }^{24}$ Visual function (eg, driving at night and working with a computer) significantly improved after starting CsA. ${ }^{21}$ Other observational studies conducted in Korea ${ }^{30}$ and Italy ${ }^{31}$ have also reported decreased dry eye symptoms with CsA usage.

In severe dry eye, more frequent dosing of CsA may help improve bioavailability of the drug and increase its efficacy. Accumulation of CsA in ocular tissues is increased with repeated administration. ${ }^{32}$ Dastjerdi et al retrospectively investigated a small cohort of graft versus host disease and Sjogren's syndrome patients with an inadequate response to standard twice-daily CsA administration after an average of 5.2 months. After CsA dosing was increased to three to four times per day, $68.2 \%$ of patients reported improvement in dry eye symptoms. ${ }^{33,34}$

\section{Patient satisfaction}

Patient satisfaction with CsA has been assessed in several studies. In an open-label study of 392 Korean patients treated with $\mathrm{CsA}, 72 \%$ reported that they were satisfied or very satisfied with CsA treatment. ${ }^{30}$ In a large survey study (financially supported by Allergan, Inc.) of 3,145 dry eye patients in the US, 79\% reported taking CsA as prescribed (twice daily) and this group reported higher satisfaction with the medication and an increased willingness to continue to medication compared to patients who reported missing doses ( $87 \%$ vs $31 \%$ ). There was also an association between patients taking $\mathrm{CsA}$ as prescribed and more rapid onset of reported increase in tear production. ${ }^{35}$ In an openlabel extension study of the Phase III CsA clinical trials, the majority of patients reported that they would continue CsA $(95.2 \%)$ and that they would recommend it to other DED patients $(97.9 \%) .{ }^{36}$ However, Stonecipher et al reviewed health claims data on CsA usage and found that on average patients only filled 4.44 months of medication over a 12 -month period and $18 \%$ of all dry eye patients filled only a 1-month supply. ${ }^{12}$

Cost-utility analysis is a form of cost-effectiveness analysis that can help determine the cost of an intervention in terms of quality of life. Brown et al found that CsA use was associated with a $4.3 \%$ value gain (improvement in quality of life) compared to lubricant therapy in patients with moderateto-severe dry eye. This value gain is similar to what has been reported for glutarl-coenzyme A (HMG-CoA) reductase inhibitors (statins) for the treatment of hyperlipidemia. ${ }^{37}$ 


\section{Artificial tear usage}

Several studies have demonstrated a decrease in artificial tear usage in patients treated with $\mathrm{CsA} .{ }^{8}$ In the large randomized clinical trials of CsA, there was a statistically significant decrease in artificial tear use with CsA treatment. ${ }^{14}$ In the follow-up open-label extension trial, Barber et al reported decreased frequency of artificial tears in CsA treated patients from 7.6 times per day to 3.8 times per day ${ }^{36}$ Roberts et al evaluated CsA in combination with punctual plugs and found a statistically significant decrease in artificial tear usage with CsA alone (mean use declined by 3.2 applications/day) and in combination with punctual plugs (mean use declined by 3.9 applications/day). ${ }^{38}$ In a survey study of 3,145 dry eye patients using CsA, 1,899 (79\%) patients were still using concomitant artificial tears. Of these patients, $73 \%$ reported using artificial tears less frequently than prior to starting CsA. ${ }^{35}$ Similarly, Stonecipher et al assessed self-reported artificial tear use among 5,884 patients taking CsA and found that after 60 days of CsA treatment $62 \%$ of patients reported using artificial tears "less than before". ${ }^{29}$

\section{Onset of cyclosporine effect}

Symptom relief has been reported to occur between 3 weeks and 3 months after initiating CsA treatment. In a survey of 144 patients participating in an extension study of the initial clinical trial of CsA (both $0.05 \%$ and $0.1 \%$ formulation), $62.5 \%$ reported that their dry eye symptoms began to resolve after the first 3 months of treatment. ${ }^{36}$ Patient-reported onset of symptom relief was faster in two large survey studies involving $>8,000$ dry eye patients taking CsA in which more than half of patients reported CsA was effective within $3-5$ weeks. ${ }^{29,35}$ Both surveys were based on patient self-report and it is unclear if reduction in symptoms was secondary to active CsA versus lubrication from CsA vehicle. Not all patients, however, report benefit from CsA. In a prospective study of 158 patients treated with CsA, $22 \%$ of patients reported no change in their dry eye symptoms as measured by OSDI over an average 8 to 10 month follow-up period..$^{20}$

\section{Side effects of cyclosporine}

The majority of clinical trials investigating CsA for the treatment of dry eye evaluated adverse events and drug safety. No vision-threatening adverse events have been reported in the literature, and topical CsA does not result in detection of significant systemic levels of drug. ${ }^{14,34}$ The most common reported side effect of $\mathrm{CsA}$ is ocular burning, reported in $\sim 17 \%$ of patients. ${ }^{10}$ Ocular burning is the most cited reason for discontinuation of CsA with approximately $3 \%$ of patients stopping the medication secondary to this side effect. ${ }^{14,20,39}$

Topical steroid use prior to initiation of CsA may help reduce burning sensation. ${ }^{40-42}$ In a study by Sheppard et al, pretreatment with topical loteprednol etabonate $0.5 \%$ started 2 weeks prior to CsA and then continued for 60 days resulted in reduced burning with $\mathrm{CsA}$ administration and faster onset of symptom reduction (15 days in patients treated with CsA and steroid vs 45 days in patients treated with CsA and artificial tears). ${ }^{40}$ There was no long-term follow-up to assess signs and symptoms of dry eye after pretreatment with steroid was stopped and CsA was continued. Mah et al evaluated the impact of a second trial of CsA in patients who had previously discontinued CsA treatment largely secondary to burning sensation on administration. Nearly half $(42.9 \%)$ of patients remained on CsA for 12 months or more during the second trial and many were pretreated or concurrently treated with topical steroid. ${ }^{39}$ Other options to help lessen side effects of CsA include cold application of the medication by keeping it refrigerated ${ }^{33}$ and patient education. ${ }^{39}$

Restasis is formulated as $0.05 \%$ CsA emulsion of castor oil in water. This formulation is linked to commonly reported ocular side effects, including burning and stinging. Other formulations of CsA have been investigated in clinical trials, including a cationic emulsion ${ }^{43}$ and aqueous solution ${ }^{44}$ and have been found to be therapeutic. New drug delivery systems are an ongoing area of research and may not only improve the clinical side effect profile, but also improve drug bioavailability and effectiveness. ${ }^{45}$

\section{Long-term evaluation of cyclosporine}

Very few studies have evaluated long-term follow-up of patients treated with CsA and uncertainty remains on what the optimal length of treatment is. In one systematic review of 18 randomized trials evaluating CsA in DED, the mean follow-up period was only 5.4 months, and no study collected outcome data for $>12$ months. ${ }^{8}$ Barber et al followed patients enrolled in the CsA Phase III clinical trials ${ }^{36}$ in an open-label extension trial. Patients were treated with $0.1 \%$ concentration of cyclosporine rather than the FDA-approved $0.05 \%$ concentration because the study was planned prior to completion of the Phase III clinical trial. There was no statistically significant improvement in patient-reported dry eye symptoms or Schirmer score during the 12-month extension period compared to findings reported at the end of the initial study period. The long-term adverse event profile was similar to what was reported in the earlier studies. ${ }^{14,36}$ 
A small retrospective case series by Wilson and Perry evaluated whether CsA can be discontinued without recurrence of dry eye symptoms. Patients with complete resolution of signs and symptoms of dry eye after at least 6 months of CsA treatment were instructed to stop the medication. In $71 \%(12 / 17)$ of these patients, dry eye symptoms recurred and CsA was reinitiated indefinitely. In 5 patients, there was no recurrence of signs or symptoms of dry eye for 12 or more months after discontinuation of CsA. Given the small number of patients, it was not possible to distinguish any specific characteristics that might distinguish patients who remained symptomfree from those who had recurrence of symptoms. ${ }^{46}$

\section{Cyclosporine and prevention of DED progression}

CsA may help prevent DED progression. In a study by Rao, 58 patients were randomized to CsA or artificial tears and followed for 12 months. Significantly fewer patients treated with CsA had progression of disease severity (defined by more severe signs and symptoms of DED) compared to patients treated with artificial tears $(6 \%$ vs $32 \%$, respectively).$^{47}$ In a follow-up study, a cross-over design was used to assess dry eye symptoms after CsA withdrawal. In a subset of patients treated with CsA for 12 months, the medication was withdrawn and signs and symptoms of dry eye assessed. Half of patients who stopped CsA developed more severe disease compared to none of the patients who continued on CsA. The author suggested that CsA withdrawal led to disease progression and argued for the necessity of maintenance therapy. ${ }^{48}$ In contrast, $\mathrm{Su}$ et al evaluated the impact of decreasing CsA frequency rather than stopping the medication. Patients who had completed at least 12 months of twice-daily CsA treatment and were in remission were randomized to continue twice-daily application of CsA or to decrease to once-daily application. Objective measures of DED were similar between these two groups. Interestingly, patients in the once-daily group had significantly improved OSDI scores compared to the twice-daily group (15.91 vs 22.62). A small percentage (14\%) of the once-daily patients did not tolerate the decreased medication dosing and resumed twice-daily dosing. ${ }^{49}$

\section{Physician perspective on the use of topical cyclosporine $0.05 \%$}

Relatively little has been published specifically evaluating the physician experience with CsA for the treatment of DED. There is some evidence to suggest that CsA is accepted and frequently prescribed by eye care providers for the treatment of DED. ${ }^{50}$ The American Academy of Ophthalmology Preferred Practice Pattern ${ }^{11}$ includes CsA in the discussion on dry eye management. Furthermore, a retrospective study of dry eye medication use and expenditures in the US showed an increase in dry eye medication prescriptions from 2001 to 2006 that was largely driven by CsA. From 2003 to 2004 (immediately after the FDA approval of CsA), CsA accounted for $68 \%$ of dry eye related prescriptions and this increased to $84 \%$ from 2005 to $2006 .{ }^{51}$

Despite its frequent use, physician assessment of the efficacy of CsA is mixed. Mah et al retrospectively evaluated patients who received a second trial of CsA after a prior treatment failure. Physicians reported that in $80 \%$ of patients clinical benefit was achieved. The details of the physician survey were not reported in the paper. ${ }^{39}$ Physician evaluation of global patient response to CsA treatment was an outcome measure of the largest randomized controlled clinical trial of CsA. Patients in all treatment groups, including vehicle control, improved over the course of the study. Response to CsA was only significantly better than vehicle in patients treated with the $0.1 \%$ formulation at 3 and 4 months of follow-up. At 6 months, however, a similar percentage of patients exhibited improvement (defined as "slight response or better") in the CsA group and vehicle control group (68.5\% vs $63.0 \%){ }^{14}$ In a survey of 100 eye care providers, $68.4 \%$ of respondents reported that CsA treatment failed in $20 \%$ or more of their dry eye patients. ${ }^{23}$

\section{Topical cyclosporine $0.05 \%$ in specific dry eye populations}

The majority of studies focus on moderate-to-severe dry eye. However, patients with mild disease may benefit from CsA as well. In a prospective study of 158 consecutive dry eye patients treated with CsA, $74.1 \%$ of patients with mild dry eye showed improvement in signs and symptoms. ${ }^{20}$

CsA has also been evaluated in specific subtypes of severe dry eye, including Sjogren's syndrome, ${ }^{52}$ Stevens Johnson syndrome,${ }^{53}$ rosacea, ${ }^{54}$ graft versus host disease, ${ }^{55}$ and chronic mustard gas injury. ${ }^{56,57}$ Most of these studies are small openlabel case series. In general, CsA improved at least some signs and symptoms of disease in these subtypes.

Other studies have evaluated CsA for dry eye in specific settings, including post-cataract surgery, ${ }^{58}$ contact lens use, ${ }^{59}$ meibomian gland disease, ${ }^{60}$ and laser in situ keratomileusis (LASIK) surgery. ${ }^{61,62}$ Most of these studies are small and the results of the efficacy of CsA were mixed. 


\section{Conclusion and future directions}

In general, CsA significantly improved signs of DED in most randomized controlled clinical trials. The impact of CsA on patient outcomes is more variable, although most studies show an improvement in at least one symptom of DED. CsA is commonly prescribed for DED and has been incorporated into practice guidelines. However, physician assessment of patient response to CsA has been mixed.

The multifactorial nature of DED adds to the challenge of evaluating the efficacy of CsA. Further research into better understanding the pathophysiology of dry eye may help identify which patients might benefit the most from treatment. In addition, adding minimally invasive objective metrics as biomarkers for DED may improve our understanding of the disease, improve classification, and assist in determining treatment efficacy. ${ }^{63,64}$ For example, matrix metalloproteinase (MMP-9) is upregulated in inflammation and has been investigated as a biomarker in DED; an in-office test that detects elevated MMP-9 in tears is now available (InflammaDry ${ }^{\mathrm{TM}}$ RPS Diagnostics, Sarasota, FL, USA). A recent retrospective study evaluated response to CsA in InflammaDry positive and negative patients and suggested identifying dry eye patients with objective evidence of inflammation may help predict patient response to treatment. ${ }^{65}$

A review of the literature on CsA for DED as presented above does offer some guidance for clinicians. There is randomized controlled evidence that $\mathrm{CsA}$ can improve both signs and symptoms of DED in some patients with reported onset of efficacy ranging from 3 weeks to 3 months after initiation. Although burning on application is a commonly reported side effect, the medication is otherwise noted to be safe with no serious adverse events reported. Clinicians should be aware of the uncertainty in the literature to date on the exact population of dry eye patients who may benefit from CsA therapy and the appropriate duration of therapy and may communicate this with patients when considering initiating CsA therapy. CsA does appear to have a role in the treatment of DED patients, although it is clearly not effective for all dry eye patients.

In summary, the available literature to date is quite heterogeneous. Sacchetti et al attempted a meta-analysis of the randomized controlled trials of CsA and concluded that "statistical comparison of CsA efficacy through a meta-analysis of data was not possible." The difference in outcomes, time point for evaluation, and variation in clinical patient population were cited as reasons contributing to the inability to perform a statistical meta-analysis. ${ }^{8}$ Two subsequent meta-analyses were completed and demonstrated significant improvements in some dry eye signs and symptoms. ${ }^{18,19}$ Again, however, the analyses highlight the diversity of trial design and the need for more standardized assessment in order to draw more robust conclusions on CsA efficacy. Future research should also seek to address remaining uncertainties in the literature, including the optimal length of treatment and long-term impact of CsA.

\section{Acknowledgment}

This study was supported, in part, by the Toni and Martin Sosnoff Fund.

\section{Disclosure}

Dr Asbell has received research funding from Alcon and MC2 Therapeutics and has participated in advisory boards by Alcon/Novartis, Allergan, and Shire. The authors report no other conflicts of interest in this work.

\section{References}

1. Yu J, Asche CV, Fairchild CJ. The economic burden of dry eye disease in the United States: a decision tree analysis. Cornea. 2011;30(4): 379-387.

2. Bron AJ, Tomlinson A, Foulks GN, et al. Rethinking dry eye disease: a perspective on clinical implications. Ocul Surf. 2014;12(2 Suppl): S1-S31.

3. The definition and classification of dry eye disease: report of the definition and classification subcommittee of the International Dry Eye WorkShop (2007). Ocul Surf. 2007;5(2):75-92.

4. Friedman NJ. Impact of dry eye disease and treatment on quality of life. Curr Opin Ophthalmol. 2010;21(4):310-316.

5 . Research in dry eye: report of the research subcommittee of the International Dry Eye WorkShop (2007). Ocul Surf. 2007;5(2):179-193.

6. Wei Y, Asbell PA. The core mechanism of dry eye disease is inflammation. Eye Contact Lens. 2014;40(4):248-256.

7. Holland EJ, Luchs J, Karpecki PM, et al. Lifitegrast for the treatment of dry eye disease: results of a Phase III, randomized, double-masked, placebocontrolled trial (OPUS-3). Ophthalmology. 2017;124(1):53-60.

8. Sacchetti M, Mantelli F, Lambiase A, Mastropasqua A, Merlo D, Bonini S. Systematic review of randomized clinical trials on topical ciclosporin A for the treatment of dry eye disease. Br J Ophthalmol. 2014;98(8):1016-1022.

9. Ames P, Galor A. Cyclosporine ophthalmic emulsions for the treatment of dry eye: a review of the clinical evidence. Clin Investig (Lond). 2015;5(3):267-285.

10. Restasis (cyclosporine ophthalmic emulsion) $0.05 \%$ full prescribing information, Allergan Inc. Available from: https:/www.allergan.com/ assets/pdf/restasis_pi.pdf. Accessed March 22, 2017.

11. American Academy of Ophthalmology Cornea/External Disease Panel. Preferred Practice Pattern ${ }^{\circledR}$ Guidelines. Dry Eye Syndrome. San Francisco, CA: American Academy of Ophthalmology.

12. Stonecipher KG, Chia J, Onyenwenyi A, Villanueva L, Hollander DA. Health claims database study of cyclosporine ophthalmic emulsion treatment patterns in dry eye patients. Ther Clin Risk Manag. 2013; 9:409-415.

13. Alves M, Fonseca EC, Alves MF, et al. Dry eye disease treatment: a systematic review of published trials and a critical appraisal of therapeutic strategies. Ocul Surf. 2013;11(3):181-192.

14. Sall K, Stevenson OD, Mundorf TK, Reis BL. Two multicenter, randomized studies of the efficacy and safety of cyclosporine ophthalmic emulsion in moderate to severe dry eye disease. CsA Phase 3 Study Group. Ophthalmology. 2000;107(4):631-639. 
15. Stevenson D, Tauber J, Reis BL. Efficacy and safety of cyclosporin A ophthalmic emulsion in the treatment of moderate-to-severe dry eye disease: a dose-ranging, randomized trial. The Cyclosporin A Phase 2 Study Group. Ophthalmology. 2000;107(5):967-974.

16. Foulks GN. Topical cyclosporine for treatment of ocular surface disease. Int Ophthalmol Clin. 2006;46(4):105-122.

17. Chen M, Gong L, Sun X, et al. A comparison of cyclosporine $0.05 \%$ ophthalmic emulsion versus vehicle in Chinese patients with moderate to severe dry eye disease: an eight-week, multicenter, randomized, double-blind, parallel-group trial. J Ocul Pharmacol Ther. 2010; 26(4):361-366.

18. Zhou XQ, Wei RL. Topical cyclosporine A in the treatment of dry eye: a systematic review and meta-analysis. Cornea. 2014;33(7): 760-767

19. Wan KH, Chen LJ, Young AL. Efficacy and safety of topical $0.05 \%$ cyclosporine eye drops in the treatment of dry eye syndrome: a systematic review and meta-analysis. Ocul Surf. 2015;13(3):213-225.

20. Perry HD, Solomon R, Donnenfeld ED, et al. Evaluation of topical cyclosporine for the treatment of dry eye disease. Arch Ophthalmol. 2008;126(8):1046-1050.

21. Stonecipher KG, Torkildsen GL, Ousler GW 3rd, Morris S, Villanueva L, Hollander DA. The IMPACT study: a prospective evaluation of the effects of cyclosporine ophthalmic emulsion $0.05 \%$ on ocular surface staining and visual performance in patients with dry eye. Clin Ophthalmol. 2016;10:887-895.

22. Schein OD, Tielsch JM, Munoz B, Bandeen-Roche K, West S. Relation between signs and symptoms of dry eye in the elderly. A populationbased perspective. Ophthalmology. 1997;104(9):1395-1401.

23. Williamson JF, Huynh K, Weaver MA, Davis RM. Perceptions of dry eye disease management in current clinical practice. Eye Contact Lens. 2014;40(2):111-115.

24. Miller KL, Walt JG, Mink DR, et al. Minimal clinically important difference for the ocular surface disease index. Arch Ophthalmol. 2010;128(1):94-101.

25. Park Y, Song JS, Choi CY, Yoon KC, Lee HK, Kim HS. A randomized multicenter study comparing $0.1 \%, 0.15 \%$, and $0.3 \%$ sodium hyaluronate with $0.05 \%$ cyclosporine in the treatment of dry eye. J Ocul Pharmacol Ther. 2017;33(2):66-72.

26. Yang JM, Choi W, Kim N, Yoon KC. Comparison of topical cyclosporine and diquafosol treatment in dry eye. Optom Vis Sci. 2015; 92(9):e296-e302.

27. Kim EC, Choi JS, Joo CK. A comparison of vitamin A and cyclosporine a $0.05 \%$ eye drops for treatment of dry eye syndrome. Am JOphthalmol. 2009;147(2):206-13.e3.

28. Saturni S, Bellini F, Braido F, et al. Randomized controlled trials and real life studies. Approaches and methodologies: a clinical point of view. Pulm Pharmacol Ther. 2014;27(2):129-138.

29. Stonecipher K, Perry HD, Gross RH, Kerney DL. The impact of topical cyclosporine A emulsion $0.05 \%$ on the outcomes of patients with keratoconjunctivitis sicca. Curr Med Res Opin. 2005;21(7):1057-1063.

30. Byun YS, Rho CR, Cho K, Choi JA, Na KS, Joo CK. Cyclosporine $0.05 \%$ ophthalmic emulsion for dry eye in Korea: a prospective, multicenter, open-label, surveillance study. Korean J Ophthalmol. 2011;25(6): 369-374.

31. Iaccheri B, Torroni G, Cagini C, et al. Corneal confocal scanning laser microscopy in patients with dry eye disease treated with topical cyclosporine. Eye (Lond). 2017;31(5):788-794.

32. Acheampong AA, Shackleton M, Tang-Liu DD, Ding S, Stern ME, Decker R. Distribution of cyclosporin A in ocular tissues after topical administration to albino rabbits and beagle dogs. Curr Eye Res. 1999; 18(2):91-103.

33. Dastjerdi MH, Hamrah P, Dana R. High-frequency topical cyclosporine $0.05 \%$ in the treatment of severe dry eye refractory to twice-daily regimen. Cornea. 2009;28(10):1091-1096.

34. Gire AI, Karakus S, Ingrodi SM, Akpek EK. Frequent dosing of topical cyclosporine A for severe ocular surface disease. J Ocular Pharmacol Ther. 2016;32(3):150-154.
35. Trattler W, Katsev D, Kerney D. Self-reported compliance with topical cyclosporine emulsion $0.05 \%$ and onset of the effects of increased tear production as assessed through patient surveys. Clin Ther. 2006; 28(11):1848-1856.

36. Barber LD, Pflugfelder SC, Tauber J, Foulks GN. Phase III safety evaluation of cyclosporine $0.1 \%$ ophthalmic emulsion administered twice daily to dry eye disease patients for up to 3 years. Ophthalmology. 2005;112(10):1790-1794.

37. Brown MM, Brown GC, Brown HC, Peet J, Roth Z. Value-based medicine, comparative effectiveness, and cost-effectiveness analysis of topical cyclosporine for the treatment of dry eye syndrome. Arch Ophthalmol. 2009;127(2):146-152.

38. Roberts CW, Carniglia PE, Brazzo BG. Comparison of topical cyclosporine, punctal occlusion, and a combination for the treatment of dry eye. Cornea. 2007;26(7):805-809.

39. Mah F, Milner M, Yiu S, Donnenfeld E, Conway TM, Hollander DA. PERSIST: Physician's evaluation of Restasis((R)) satisfaction in second trial of topical cyclosporine ophthalmic emulsion 0.05\% for dry eye: a retrospective review. Clin Ophthalmol. 2012;6: 1971-1976.

40. Sheppard JD, Donnenfeld ED, Holland EJ, et al. Effect of loteprednol etabonate $0.5 \%$ on initiation of dry eye treatment with topical cyclosporine 0.05\%. Eye Contact Lens. 2014;40(5):289-296.

41. Sheppard JD, Scoper SV, Samudre S. Topical loteprednol pretreatment reduces cyclosporine stinging in chronic dry eye disease. $J$ Ocul Pharmacol Ther. 2011;27(1):23-27.

42. Byun YJ, Kim TI, Kwon SM, et al. Efficacy of combined $0.05 \%$ cyclosporine and 1\% methylprednisolone treatment for chronic dry eye. Cornea. 2012;31(5):509-513.

43. Leonardi A, Van Setten G, Amrane M, et al. Efficacy and safety of $0.1 \%$ cyclosporine A cationic emulsion in the treatment of severe dry eye disease: a multicenter randomized trial. Eur J Ophthalmol. 2016; 26(4):287-296.

44. Baiza-Duran L, Medrano-Palafox J, Hernandez-Quintela E, LozanoAlcazar J, Alaniz-de la OJ. A comparative clinical trial of the efficacy of two different aqueous solutions of cyclosporine for the treatment of moderate-to-severe dry eye syndrome. Br J Ophthalmol. 2010;94(10): 1312-1315.

45. Agarwal P, Rupenthal ID. Modern approaches to the ocular delivery of cyclosporine A. Drug Discov Today. 2016;21(6):977-988.

46. Wilson SE, Perry HD. Long-term resolution of chronic dry eye symptoms and signs after topical cyclosporine treatment. Ophthalmology. 2007;114(1):76-79.

47. Rao SN. Topical cyclosporine $0.05 \%$ for the prevention of dry eye disease progression. J Ocul Pharmacol Ther. 2010;26(2): $157-164$.

48. Rao SN. Reversibility of dry eye deceleration after topical cyclosporine 0.05\% withdrawal. J Ocul Pharmacol Ther. 2011;27(6):603-609.

49. Su MY, Perry HD, Barsam A, et al. The effect of decreasing the dosage of cyclosporine A $0.05 \%$ on dry eye disease after 1 year of twice-daily therapy. Cornea. 2011;30(10):1098-1104.

50. Song JS, Hyon JY, Lee D, et al. Current practice pattern for dry eye patients in South Korea: a multicenter study. Korean JOphthalmol. 2014; 28(2):115-121.

51. Galor A, Zheng DD, Arheart KL, et al. Dry eye medication use and expenditures: data from the medical expenditure panel survey 2001 to 2006. Cornea. 2012;31(12):1403-1407.

52. Deveci H, Kobak S. The efficacy of topical $0.05 \%$ cyclosporine A in patients with dry eye disease associated with Sjogren's syndrome. Int Ophthalmol. 2014;34(5):1043-1048.

53. Prabhasawat P, Tesavibul N, Karnchanachetanee C, Kasemson S. Efficacy of cyclosporine $0.05 \%$ eye drops in Stevens Johnson syndrome with chronic dry eye. J Ocul Pharmacol Ther. 2013;29(3): 372-377.

54. Arman A, Demirseren DD, Takmaz T. Treatment of ocular rosacea: comparative study of topical cyclosporine and oral doxycycline. Int $J$ Ophthalmol. 2015;8(3):544-549. 
55. Lelli GJ Jr, Musch DC, Gupta A, Farjo QA, Nairus TM, Mian SI. Ophthalmic cyclosporine use in ocular GVHD. Cornea. 2006;25(6): 635-638.

56. Jadidi K, Panahi Y, Ebrahimi A, Mafi M, Nejat F, Sahebkar A. Topical cyclosporine a for treatment of dry eye due to chronic mustard gas injury. J Ophthalmic Vis Res. 2014;9(4):417-422.

57. Jadidi K, Ebrahimi A, Panahi Y, et al. Topical cyclosporine a for mustard gas induced ocular surface disorders. J Ophthalmic Vis Res. 2015; 10(1):21-25.

58. Chung YW, Oh TH, Chung SK. The effect of topical cyclosporine $0.05 \%$ on dry eye after cataract surgery. Korean J Ophthalmol. 2013; 27(3):167-171.

59. Willen CM, McGwin G, Liu B, Owsley C, Rosenstiel C. Efficacy of cyclosporine $0.05 \%$ ophthalmic emulsion in contact lens wearers with dry eyes. Eye Contact Lens. 2008;34(1):43-45.

60. Prabhasawat P, Tesavibul N, Mahawong W. A randomized double-masked study of $0.05 \%$ cyclosporine ophthalmic emulsion in the treatment of meibomian gland dysfunction. Cornea. 2012;31(12):1386-1393.
61. Torricelli AA, Santhiago MR, Wilson SE. Topical cyclosporine a treatment in corneal refractive surgery and patients with dry eye. $J$ Refract Surg. 2014;30(8):558-564.

62. Salib GM, McDonald MB, Smolek M. Safety and efficacy of cyclosporine $0.05 \%$ drops versus unpreserved artificial tears in dry-eye patients having laser in situ keratomileusis. J Cataract Refract Surg. 2006;32(5):772-778

63. Epstein SP, Gadaria-Rathod N, Wei Y, Maguire MG, Asbell PA. HLA-DR expression as a biomarker of inflammation for multicenter clinical trials of ocular surface disease. Exp Eye Res. 2013;111: 95-104.

64. Wei Y, Gadaria-Rathod N, Epstein S, Asbell P. Tear cytokine profile as a noninvasive biomarker of inflammation for ocular surface diseases: standard operating procedures. Invest Ophthalmol Vis Sci. 2013; 54(13):8327-8336.

65. Sambursky R. Presence or absence of ocular surface inflammation directs clinical and therapeutic management of dry eye. Clin Ophthalmol. 2016; 10:2337-2343.
Clinical Ophthalmology

\section{Publish your work in this journal}

Clinical Ophthalmology is an international, peer-reviewed journal covering all subspecialties within ophthalmology. Key topics include: Optometry; Visual science; Pharmacology and drug therapy in eye diseases; Basic Sciences; Primary and Secondary eye care; Patient Safety and Quality of Care Improvements. This journal is indexed on

\footnotetext{
Submit your manuscript here: http://www.dovepress.com/clinical-ophthalmology-journal
}

\section{Dovepress}

PubMed Central and CAS, and is the official journal of The Society of Clinical Ophthalmology (SCO). The manuscript management system is completely online and includes a very quick and fair peer-review system, which is all easy to use. Visit http://www.dovepress.com/ testimonials.php to read real quotes from published authors. 